Reprod. Nutr. Dévelop., 1982, 22 (5), 735-752.

\title{
Influence des ciliés du rumen sur la digestion de différents glucides chez le mouton. I. - Utilisation des glucides pariétaux (cellulose et hémicelluloses) et de l'amidon
}

\author{
J. P. JOUANY, J. SENAUD $\left(^{*}\right)$
}

Laboratoire de la Digestion des Ruminants, I.N.R.A. Theix, 63110 Beaumont, France.

(*) L.A. CNRS n० 138, Biologie des Protistes, Université de Clermont II, 63170 Aubière, France.

Summary. Effect of rumen ciliates on the digestion of different carbohydrates in sheep. I. - Utilization of cell wall carbohydrates (cellulose and hemicelluloses) and of starch.

Two diets rich in cell-wall carbohydrates or starch were given to 10 rumen-fistulated sheep; two sheep were defaunated and the others were inoculated with Polyplastron multivesiculatum $(P)$ or Entodinium sp. $(E)$, or both $(P+E)$, or with conventional fauna.

Ciliate biomass was greater when the animals were fed a high starch diet than when the diet was rich in cell-wall carbohydrates (table 2). With both diets, the Entodinium genus in the mixed fauna sampling predominated.

We showed that Polyplastron was directly involved in cell-wall carbohydrate breakdown, while Entodinium capacity to digest cellulose remained low. We noted that with a diet rich in cellulose and hemicelluloses, bacterial cellulolytic activity was improved by the presence of ciliates in the rumen but was decreased with the " starch ") diet (table 3). The greater VFA concentration observed in the faunated animals expressed ciliate effect on the fermentations as well as activation of bacterial metabolism. With a high starch diet, the Entodinium sp. ciliates may have a buffering effect on the $\mathrm{pH}$ values in the rumen by limiting bacterial fermentation after food intake and by prolonging starch digestion during the day (table 4).

The composition of the VFA mixture was modified by ciliate inoculation. The molar proportion of butyric acid always increased, while that of acetic and propionic acids evolved differently according to the diets and the ciliates (table 4).

The higher ammonia concentration in the rumen liquor observed in faunated animals (table 4) could be explained either by the breakdown of both feed and bacterial proteins ingested by ciliates or by a lower ammonia nitrogen incorporation by fewer bacteria. Statistical analyses were used to explain the specific effect of $P$ and $E$ and also the interactions between them and between each of them and the diets.

\section{Introduction.}

Les glucides qui représentent environ 70 p. 100 de la matière sèche des aliments du Ruminant, sont principalement dégradés dans le rumen par les bactéries 
et les protozoaires. On attribue un rôle prépondérant aux bactéries alors que l'influence des protozoaires ciliés sur la digestion dans le rumen est restée longtemps méconnue (Hungate, 1966) ; elle est, aujourd'hui encore, fortement controversée (Prins et Clarke, 1979).

La plupart des études relatives au métabolisme glucidique des ciliés ont été effectuées jusque-là in vitro (Hungate, 1955; Oxford, 1955 ; Eadie et Howard, 1963 ; Coleman, 1969 a et b, 1970 ; Coleman, Davies et Cash, 1972 ; BonhommeFlorentin, 1975). Elles ont permis de mettre en évidence l'existence d'enzymes capables d'hydrolyser les glucides et de préciser la nature des principaux produits terminaux de la fermentation de différents glucides incorporés dans les milieux de culture. Ces résultats sont toutefois difficilement applicables in vivo puisque les conditions de milieu (apport de nutriment, élimination des produits formés, conditions physico-chimiques, ...) y sont très différentes (Hungate, 1942, 1943 ; Coleman, 1960 ; Gutierrez et Davis, 1962 ; Clarke, 1963 ; Mah, 1964). C'est pourquoi nous avons voulu étudier in vivo l'influence de deux genres de ciliés les plus fréquemment rencontrés dans le rumen de mouton (Polyplastron et Entodinium) sur la digestion des principaux glucides des aliments du Ruminant : glucides pariétaux (cellulose et hémicelluloses), amidon, inuline, saccharose et lactose. Pour cela, nous avons utilisé des animaux dont le rumen était soit défauné, soit inoculé avec la seule espèce Polyplastron multivesiculatum ou le seul genre Entodinium, soit biinoculé simultanément avec les deux ciliés, soit conventionnel. Nous avons mesuré la digestibilité des principaux constituants des régimes et les paramètres de la digestion dans le rumen. Nous présentons dans cette première partie, les résultats relatifs à la digestion des régimes riches en glucides pariétaux et en amidon.

\section{Matériel et méthodes.}

\section{Aliments.}

Deux régimes ont été successivement étudiés (tabl. 1) : le premier était composé de foin de prairie naturelle distribué sous forme hachée $(954 \mathrm{~g} \mathrm{M}$.S. par jour et par animal) ; le second était constitué d'orge aplatie (604 g de M.S. par jour et par animal), du même foin que précédemment (477 g de M.S. par jour et par animal) et de tourteau d'arachide (70 g de M.S. par jour et par animal). Les deux régimes étaient isoazotés et les quantités des principaux glucides ingérés par les animaux étaient voisines : $21 \mathrm{~g}$ de cellulose + hémicelluloses $/ \mathrm{kg} \mathrm{P} \mathrm{P}^{0,75} /$ jour avec le régime " cellulose » et $21,4 \mathrm{~g}$ d'amidon $/ \mathrm{kg} \mathrm{P}^{0,75} / \mathrm{jour}$ avec le régime " amidon »; avec ce dernier régime, les animaux ont également ingéré $12 \mathrm{~g}$ de cellulose + hémicelluloses $/ \mathrm{kg} \mathrm{P}^{0,75} /$ jour. Les différences dans la nature de l'énergie et de l'azote présents dans les deux régimes étudiés ont entraîné des variations importantes sur leurs valeurs respectives en PDIE et PDIN.

Les rations journalières étaient distribuées en deux repas égaux à $8 \mathrm{~h} 30$ et 16 h 30 .

\section{Animaux.}

Nous avons utilisé 10 moutons adultes de race Limousine pesant en moyenne $40 \mathrm{~kg}$ et porteur d'une fistule permanente du rumen. Ils ont été répartis en 5 lots : 
TABLEAU I

Composition des régimes (p. 100 matière sèche)

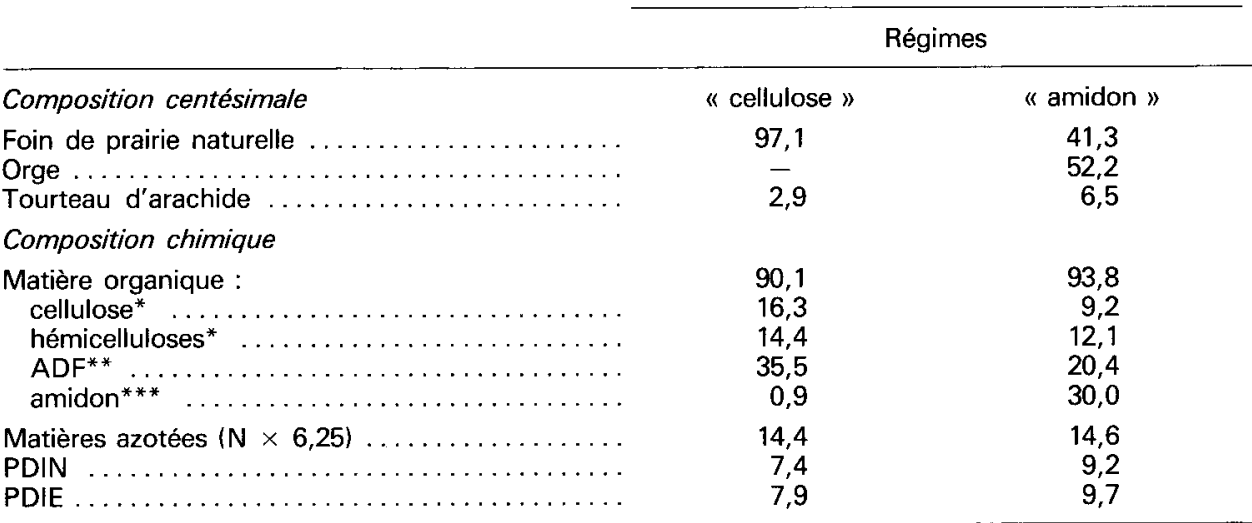

* Selon Jarrige (1961) ; ** selon Van Soest (1963) ; ** selon Thivend, Mercier et Guilbot (1965).

le premier était constitué de 2 moutons dont le rumen ne comportait pas de ciliés $(-\mathrm{C})$; les deuxième et troisième lots étaient composés chacun de deux animaux mono-inoculés, soit avec l'espèce Polyplastron multivesiculatum $(P)$, soit avec un mélange d'espèces appartenant toutes au genre Entodinium $s p .(E)$; les deux moutons du quatrième lot étaient contaminés avec les deux genres de ciliés $(P+E)$ tandis que les deux derniers moutons avaient une faune de type conventionnel $(+C)$. Les animaux à rumen non fauné ont été préparés selon la technique de Williams et Dinusson (1972) appliquée aux ovins.

Les animaux ont été maintenus en case individuelle sur litière de copeaux. Chaque lot a été isolé dans des pièces qui ne présentaient pas d'ouverture extérieure et qui ne communiquaient pas entre elles. Une ventilation mécanique assurait une circulation continue d'air entre les différentes pièces. La température et le degré d'hygrométrie ont été maintenus constants à l'aide d'un climatiseur. L'éclairage artificiel des pièces, dont la durée a été identique pour tous les animaux, était contrôlé.

\section{Préparation de l'inoculum de ciliés.}

Environ 1000 ciliés ont été triés un à un sous une loupe binoculaire, à partir d'un contenu de rumen de mouton conventionnel, à l'aide d'une micropipette munie d'une tétine. Ils ont été ensuite déposés dans une coupelle contenant du liquide de Hungate $\left(^{*}\right)$ à la température de $39-40^{\circ} \mathrm{C}$. Après 4 tris successifs dans cette solution, les ciliés ont été placés pendant environ $3 \mathrm{~h}$ à $39^{\circ} \mathrm{C}$, dans du jus de rumen préalablement filtré à $0,2 \mu$ pour éliminer les ciliés. Cette courte période d'incubation permet aux ciliés tels que Polyplastron, prédateurs d'autres protozoaires, de digérer leur proie et d'éviter ainsi les contaminations dues à la régurgi-

(*) Solution de Hungate: $\mathrm{NaCl}: 6 \mathrm{~g} ; \mathrm{NaHCO}_{3}: 1 \mathrm{~g} ; \mathrm{KH}_{2} \mathrm{PO}_{4}: 1 \mathrm{~g} ; \mathrm{MgSO}_{4}: 0,1 \mathrm{~g}$; $\mathrm{CaCl}_{2}: 0,1 \mathrm{~g}$. Compléter à 1 litre avec de l'eau distillée. 
tation d'un cilié vivant. Un dernier pipetage à la fin de l'incubation a permis d'obtenir un inoculum pur du cilié $P$. multivesiculatum que l'on introduit, à l'aide d'une pipette, dans le fond du sac ventral du rumen.

\section{Schéma expérimental.}

Pour l'ensemble des animaux, l'étude de chaque régime a duré 11 semaines. L'expérimentation s'est déroulée de la manière suivante :

- adaptation des micro-organismes du rumen au régime (3 semaines) ;

- mesure de digestibilité de la ration ( 2 semaines) ;

- prélèvements au niveau du rumen ( 2 semaines);

- mesure de l'activité cellulolytique des bactéries du rumen (2 semaines) ;

- prises de sang (2 semaines).

La durée d'un tel plan expérimental s'explique par le fait qu'il faut absolument éviter de manipuler simultanément des animaux de faune différente si on veut éviter tout risque de contamination entre animaux.

II ne nous a pas été possible d'utiliser un dispositif en carré latin puisque les animaux ont conservé chacun leur faune tout au long de ce travail.

\section{Mesures.}

L'utilisation digestive globale de la ration a été mesurée par collecte totale des fèces pendant une semaine, à l'aide de sacs maintenus en place par des harnais. La mesure a été effectuée pendant deux périodes sur chaque animal. Une aliquote représentant exactement un quart du poids frais des fèces a été séchée à l'étuve ventilée à $80^{\circ} \mathrm{C}$ pendant $24 \mathrm{~h}$ pour la détermination de la matière sèche. La fraction restante a été congelée, puis utilisée pour doser la matière organique, l'azote (Kjeldahl), la lignocellulose (ADF) selon la méthode de Van Soest (1963) et l'amidon (Thivend, Mercier et Guilbot, 1965).

Au niveau du rumen, les échantillons de contenu ont été prélevés juste avant le repas du matin puis $1 / 2 \mathrm{~h}, 1 \mathrm{~h}, 1 \mathrm{~h} 30,2 \mathrm{~h}, 3 \mathrm{~h}$ et $5 \mathrm{~h}$ après le début du repas, pendant 2 jours consécutifs. Le pH a été mesuré immédiatement après le prélèvement. Les échantillons ont ensuite été filtrés sur gaze de mousseline et conservés à $-15^{\circ} \mathrm{C}$. L'analyse des acides gras volatils (AGV) a été faite par chromatographie en phase gazeuse à l'aide d'un chromatographe Girdel $3000^{*}$ muni d'une colonne de verre longue de $1,4 \mathrm{~m}$ et de $2,16 \mathrm{~mm}$ de diamètre intérieur ; le garnissage était constitué de chromosorb 101 dont la granulométrie était de 60-80 mesh. L'injection du mélange des $A G V$ avait lieu directement dans la tête de colonne, laquelle était amovible et devait être nettoyée toutes les 50 injections afin d'éviter des phénomènes d'absorption (Jouany, 1978). L'azote ammoniacal a été dosé en continu selon la méthode de Weatherburn (1967) adaptée par Michel (1971).

La concentration en acide lactique et en glucides alcooio-solubles a été mesurée sur les échantillon de jus de rumen prélevés aux temps TO, T $1 \mathrm{~h} 30$ et T 3 h. L'acide lactique a été dosé par la méthode de Barker et Summerson (1941) : les glucides alcoolo-solubles ont été déterminés selon la méthode de Besle (1971) appliquée à l'autoanalyseur Technicon.

Nous avons mesuré l'activité cellulolytique des bactéries du rumen in vivo, selon la méthode de Demarquilly et Chenost (1969). Nous avons observé qu'en utilisant un tissu de nylon, dont la taille des mailles est petite $(<10 \mu)$, la quasi-

(*) Girdel, 51, r. de Verdun, 92150 Suresnes. 
totalité des ciliés ne peut pas pénétrer à l'intérieur des sachets. Seuls quelques Entodinium de très petite taille peuvent franchir cette barrière ; leur concentration à l'intérieur des sachets reste toutefois négligeable ( $<$ à 2 Entodinium $/ \mathrm{g}$ ). Nous savons, en outre, qu'il n'y a pas de cellulase libre dans le liquide du rumen. Dans ces conditions, la méthode donne une bonne estimation de l'activité cellulolytique des bactéries seules et non pas de l'ensemble de la population microbienne du rumen.

L'effectif moyen des populations de ciliés a été déterminé pour chaque régime par comptage des ciliés en cuve de Dolfuss pendant au moins 5 jours consécutifs, lorsque la population a atteint un état d'équilibre stable. L'analyse quantitative de cette population a été faite, d'une part, en considérant la concentration de chacune des espèces ou des genres rencontrés et, d'autre part, en tenant compte du volume occupé par chacun d'eux. Dans le premier cas, nous avons accordé la même importance à tous les ciliés, quelle que soit leur taille, alors que dans le second cas nous avons considéré que le métabolisme d'un cilié est en relation directe avec son volume et son poids. Pour évaluer le volume représenté par les ciliés, nous avons utilisé les données de Warner (1962) et de Coleman (1975) : $3,5 \times 10^{-8} \mathrm{ml}$ pour Entodinium sp. ; 5,0 $\times 10^{-7} \mathrm{ml}$ pour $P$. multivesiculatum ; $1,0 \times 10^{-6}$ pour /sotricha sp. et $3,6 \times 10^{-8} \mathrm{ml}$ pour Dasytricha ruminantium.

La mesure du volume du liquide dans le rumen a été faite deux fois sur chaque animal, selon la méthode décrite par Hyden (1961). Nous avons introduit une dose de $20 \mathrm{~g}$ de polyéthylène glycol 4000 (PEG) dissoute dans $200 \mathrm{ml}$ d'eau dans le rumen, avant le repas du matin. Les prélèvements ont été effectués aux temps $1 / 2 \mathrm{~h} ; 3 \mathrm{~h} ; 6 \mathrm{~h} ; 8 \mathrm{~h} ; 10 \mathrm{~h} ; 12 \mathrm{~h}$ et $15 \mathrm{~h}$ après l'introduction du marqueur. Le PEG a été dosé selon la méthode turbidimétrique de Hyden (1955).

Environ $20 \mathrm{ml}$ de sang périphérique ont été prélevés pendant 2 jours dans la veine jugulaire $1 \mathrm{~h}$ après le repas du matin à l'aide d'un catéther en polychlorure de vinyle de qualité chirurgicale (type vygon) placé la veille sur chaque animal. Le sang a été recueilli sous héparine, puis rapidement centrifugé à $3000 \mathrm{t} / \mathrm{min}$, pendant $10 \mathrm{~min}$ à $4{ }^{\circ} \mathrm{C}$. Le plasma a été conservé à $-15^{\circ} \mathrm{C}$. Nous avons alors mesuré la glycémie par la méthode de Trinder (1969) automatisée. La valeur de I'hématocrite a été mesurée immédiatement après avoir prélevé le sang (Charpentier, 1966).

\section{Traitement statistique des données.}

L'étude statistique des résultats a été faite par la méthode d'analyse de variance à une voie (Snedecor et Cochran, 1971) appliquée à des lots de taille différente. Le seuil de 5 p. $100(P<0,05)$ a été retenu pour la mise en évidence de différences significatives. Nous avons également effectué une analyse sur un plan factoriel $2 \times 2 \times 2$ permettant de mettre en évidence les effets de $P$, de $E$ et de la nature du régime, ainsi que les interactions entre les 3 facteurs précités.

\section{Résultats.}

Description de la faune du rumen (tabl. 2 et fig. 1).

Chez les animaux mono-inoculés recevant le régime "cellulose ", les effectifs 
Concentration (Nbre $\times 10^{3} / \mathrm{ml}$ ) des protozoaires ciliés dans fe rumen des animaux recevant les régimes "cellulose » ou " amidon » (moyenne et écart type)

\begin{tabular}{|c|c|c|c|c|c|c|c|c|c|}
\hline \multirow{2}{*}{ Régimes } & \multicolumn{9}{|c|}{ Rumen inoculé avec } \\
\hline & $(E)$ & $(P)$ & $(E)$ & $(P)$ & $(E)$ & $+(P)$ & + & (D) & $+(I)$ \\
\hline $\begin{array}{l}\text { "Cellulose " } \\
\text { «Amidon » }\end{array}$ & $\begin{array}{c}61,0 \\
+\quad 11,9^{A} \\
2050,0 \\
\pm 129,5^{A}\end{array}$ & $\begin{array}{c}3,5 \\
\pm 1,2^{\mathrm{a}} \\
2,6 \\
\pm 0,6^{\mathrm{a}}\end{array}$ & $\begin{array}{c}54,6 \\
\pm \quad 10,8^{\mathrm{A}} \\
692,8 \\
\pm 98,6^{\mathrm{B}}\end{array}$ & $\begin{array}{c}6,5 \\
\pm 2,4^{\mathrm{a}} \\
23,7 \\
\pm 2,4^{\mathrm{b}}\end{array}$ & $\begin{array}{c}180,3 \\
\pm 49,1^{\mathrm{A}} \\
2463,5 \\
\pm \quad 379,9^{\mathrm{A}}\end{array}$ & $\begin{array}{c}6,3 \\
\pm 2,5^{\mathrm{a}} \\
33,1 \\
\pm 8,4^{\mathrm{c}}\end{array}$ & & $\begin{array}{r}15,5 \\
1,6 \\
18,6 \\
+6,4\end{array}$ & $\begin{array}{c}1,3 \\
\pm 0,1 \\
6,1 \\
\pm 2,4\end{array}$ \\
\hline
\end{tabular}

(A l'intérieur d'un régime, les valeurs des ciliés appartenant à un même genre qui sont affectées de lettres différentes, sont significativement différentes au seuil de $P<0,05)$.

$(E)$ : Entodinium sp.; $(P)$ : Polyplastron multivesiculatum; $(D)$ : Dasytricha ruminantium; (/) : Isotricha prostoma.
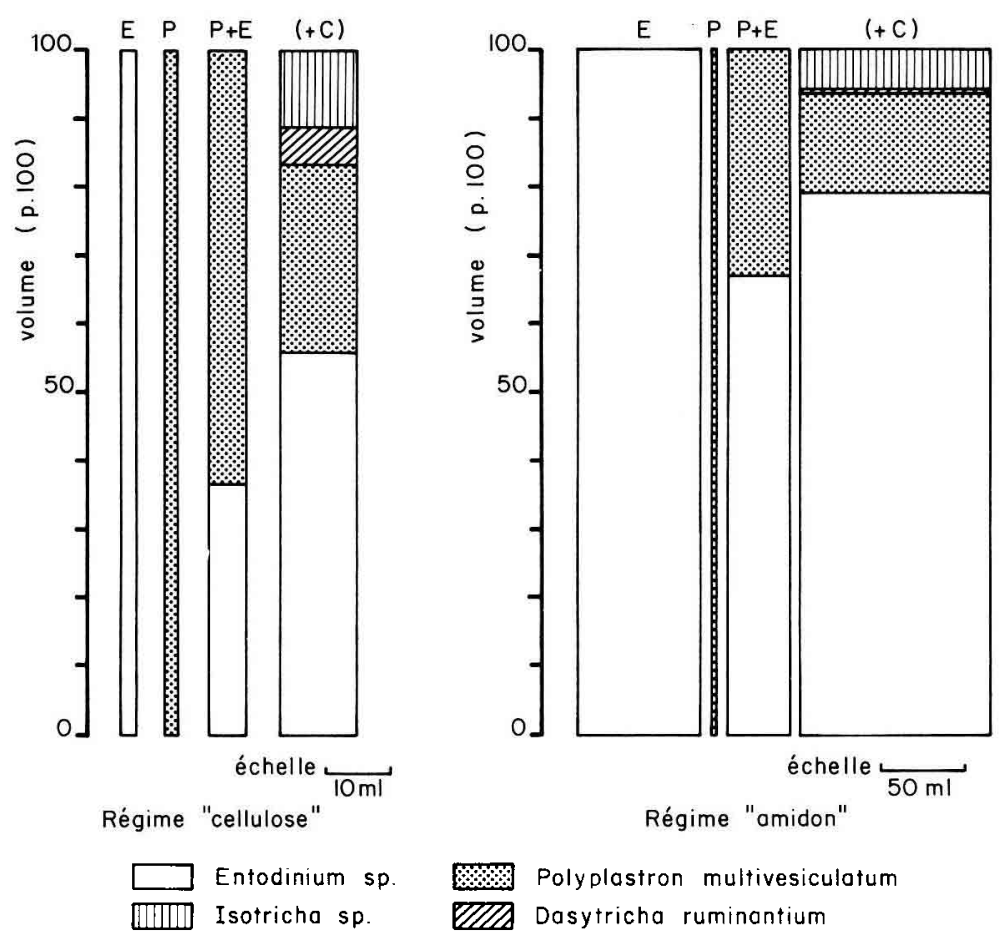

FIG. 1. - Influence du régime et de la nature de l'inoculum sur la biomasse des ciliés ( $\mathrm{ml}$ de ciliés par litre de contenu de rumen).

de $E$ et de $P$ ont été respectivement de $61 \times 10^{3}$ et $3,5 \times 10^{3}$ par $\mathrm{ml}$ ce qui, en volume, correspond à des biomasses voisines (fig. 1). Avec ce même régime, l'inoculation simultanée de $P$ et de $E$ a conduit à une population mixte de $54,6 \times 10^{3} E$ et $6,5 \times 10^{3} P$ par $\mathrm{ml}$. La présence simultanée des deux genres n'a 
donc pratiquement pas modifié l'effectif de $E$; celui de $P$, par contre, a été deux fois plus important chez les animaux bi-inoculés. Dans ces conditions, $P$ représente environ 63 p. 100 de la biomasse des ciliés dont la valeur moyenne a été environ multipliée par 2,5.

La présence d'amidon dans le régime a très nettement augmenté l'effectif moyen de $E$ (environ 33 fois plus important que celui observé avec le régime « cellulose 1$)$; en revanche, la population de $P$ a légèrement diminué. Dans ces conditions, la biomasse de $E$ correspond à environ 55 fois celle de $P$ chez les animaux mono-inoculés. La présence simultanée des deux genres a favorisé le développement de $P$ dont la concentration a été multipliée par 9 , au détriment de $E$ dont l'effectif a été trois fois plus faible que celui des animaux mono-inoculés. Ainsi $E$ et $P$ représentent respectivement 67 et 33 p. 100 de la biomasse totale des ciliés dont la valeur est environ 2 fois plus faible que celle des animaux inoculés avec $E$ et beaucoup plus importante ( 28 fois) que celle des animaux ayant $P$ seuls.

Quelle qu'ait été la nature du régime, la faune du rumen des animaux conventionnels n'a comporté que 4 genres: Entodinium (E), Isotricha (I), Polyplastron (P) et Dasytricha (D). Ces deux derniers genres ne comprenaient respectivement que les espèces Polyplastron multivesiculatum et Dasytricha ruminantium. Dans cette population mixte, c'est l'effectif de $E$ qui, en nombre, a toujours été le plus important $\left(180 \times 10^{3} / \mathrm{ml}\right.$ avec le régime " cellulose » et $2463 \times 10^{3} / \mathrm{ml}$ avec le régime « amidon $»)$, tandis que celui de $P$ et de $D$ a été respectivement de $6,3 \times 10^{3}$ et $15,5 \times 10^{3} / \mathrm{ml}$ chez les animaux nourris avec le régime "cellulose », et $33,1 \times 10^{3}$ et $18,6 \times 10^{3}$ chez ceux recevant le régime " amidon ". La population de / a toujours été plus faible $\left(1,3 \times 10^{3} / \mathrm{ml}\right.$ avec le régime "cellulose ", $6,1 \times 10^{3} / \mathrm{ml}$ avec le régime « amidon »). L'ensemble de ces données, exprimé en biomasse, montre que $E$ prend une part prépondérante aux dépens des trois autres genres (fig. 1) chez les animaux conventionnels. Cet effet est particulièrement net avec le régime " amidon ". L'addition des genres / et $D$ à $P+E$ a donc surtout favorisé le développement d'Entodinium, dont la biomasse a été environ 3 fois supérieure chez les animaux conventionnels par rapport à celle mesurée chez les animaux bi-inoculés avec $P+E$, pour les deux régimes étudiés.

Utilisation digestive de la ration (tabl. 3).

La présence de ciliés dans le rumen a toujours entraîné une augmentation de la digestibilité apparente de la matière organique. Celle-ci a toujours été particulièrement nette chez les animaux inoculés avec $P$, que ce cilié ait été présent seul ou avec $E$. L'implantation de $E$ a entraîné une augmentation plus faible, mais cependant significative, de l'utilisation digestive apparente de la matière organique avec le régime "cellulose "; dans le cas du régime " amidon ", l'évolution de ce paramètre a été identique à celle observée chez les animaux inoculés avec $P$.

D'une manière générale, la digestibilité de la lignocellulose (ADF) a augmenté chez les animaux faunés ; cette augmentation n'a toutefois pas été significative avec le seul lot d'animaux mono-inoculés avec $E$ qui recevaient le régime " cellulose $)$.

La digestibilité de l'amidon a été totale pour l'ensemble des animaux étudiés qu'elle qu'ait été la nature de la faune du rumen. 
TABLEAU 3

Utilisation digestive apparente des principaux constituants des régimes "cellulose " et " amidon "; activité cellulolytique des bactéries

\begin{tabular}{|c|c|c|c|c|c|c|c|c|}
\hline Mesure (p. 100) & $N$ & Régime & $(-C)$ & $P$ & $E$ & $P+E$ & $(+C)$ & $\begin{array}{l}\text { erreur } \\
\text { résiduelle }\end{array}$ \\
\hline CUD ${ }_{a}$ M.S. & 4 & $\begin{array}{l}\text { " cellulose " } \\
\text { " amidon " }\end{array}$ & $\begin{array}{l}68,6^{\mathrm{a}} \\
72,6^{\mathrm{a}}\end{array}$ & $\begin{array}{l}71,8^{\mathrm{b}} \\
75,7^{\mathrm{b}}\end{array}$ & $\begin{array}{l}68,9^{\mathrm{a}} \\
76,1^{\mathrm{b}}\end{array}$ & $\begin{array}{l}72,4^{\mathrm{b}} \\
77,2^{\mathrm{b}}\end{array}$ & $\begin{array}{l}70,6^{\mathrm{c}} \\
75,5^{\mathrm{b}}\end{array}$ & $\begin{array}{l}0,6 \\
1,1\end{array}$ \\
\hline CUD ${ }_{a}$ M.O. & 4 & $\begin{array}{l}\text { "cellulose" } \\
\text { "amidon" }\end{array}$ & $\begin{array}{l}68,7^{\mathrm{a}} \\
74,9^{\mathrm{a}}\end{array}$ & $\begin{array}{l}72,4^{\mathrm{b}} \\
77,3^{\mathrm{b}}\end{array}$ & $\begin{array}{l}70,0^{\mathrm{c}} \\
78,4^{\mathrm{b}}\end{array}$ & $\begin{array}{l}73,3^{\mathrm{b}} \\
78,5^{\mathrm{b}}\end{array}$ & $\begin{array}{l}70,9^{\mathrm{c}} \\
77,6^{\mathrm{b}}\end{array}$ & $\begin{array}{l}0,7 \\
0,9\end{array}$ \\
\hline $\begin{array}{c}\text { CUDa } \\
\text { lignocellulose (ADF) }\end{array}$ & 4 & $\begin{array}{l}\text { " cellulose " } \\
\text { " amidon " }\end{array}$ & $\begin{array}{l}68,9^{\mathrm{a}} \\
55,6^{\mathrm{a}}\end{array}$ & $\begin{array}{l}71,6^{\mathrm{bc}} \\
61,4^{\mathrm{b}}\end{array}$ & $\begin{array}{l}70,1^{\mathrm{ac}} \\
60,3^{\mathrm{b}}\end{array}$ & $\begin{array}{l}72,3^{\mathrm{b}} \\
60,9^{\mathrm{b}}\end{array}$ & $\begin{array}{l}71,1^{\mathrm{bc}} \\
60,0^{\mathrm{b}}\end{array}$ & $\begin{array}{l}0,8 \\
1,1\end{array}$ \\
\hline $\begin{array}{l}\text { Activité cellulolyti- } \\
\text { que des bactéries }\end{array}$ & 16 & $\begin{array}{l}\text { " cellulose " } \\
\text { " amidon" }\end{array}$ & $\begin{array}{l}38,3^{\mathrm{a}} \\
27,3^{\mathrm{a}}\end{array}$ & $\begin{array}{l}39,8^{a b} \\
25,4^{b}\end{array}$ & $\begin{array}{l}41,3^{b} \\
24,5^{b}\end{array}$ & $\begin{array}{l}41,3^{\mathrm{b}} \\
22,1^{\mathrm{c}}\end{array}$ & $\begin{array}{l}41,0^{\mathrm{b}} \\
21,1^{\mathrm{c}}\end{array}$ & $\begin{array}{l}1,9 \\
1,5\end{array}$ \\
\hline
\end{tabular}

(Les valeurs affectées de lettres différentes sont significativement différentes au seuil $P<0,05$ ).

Digestion dans le rumen (tabl. 3 et 4 ).

L'implantation du seul genre $P$ dans un rumen défauné a provoqué un accroissement significatif (de 15 à 22 p. 100) de la concentration en acides gras volatils totaux ( $A G V$ ) du jus de rumen pendant les $5 \mathrm{~h}$ qui ont suivi le début du repas et une diminution du $\mathrm{pH}$. La teneur en acide butyrique du mélange des AGV a été fortement augmentée (1,8 à 2,6 fois) au détriment de l'acide acétique et valérique. Le pourcentage molaire de l'acide propionique a évolué différemment selon la nature du régime: II a significativement augmenté lorsque les animaux ont reçu le régime riche en glucides pariétaux et diminué avec le régime " amidon ". La concentration en azote ammoniacal et en glucides alcoolosolubles n'a, par contre, pas été modifiée. L'activité cellulolytique des bactéries du rumen ainsi que la concentration en acide lactique n'ont, également, pas été influencées par la présence de $P$ lorsque les animaux ont reçu le régime riche en glucides pariétaux ; en revanche, avec le régime " amidon ", la concentration de l'acide lactique a augmenté tandis que l'activité cellulolytique a diminué.

La présence de $E$ seul a provoqué une augmentation de la concentration des AGV dans le rumen des animaux nourris avec le régime "cellulose " et une diminution avec le régime " amidon ". L'évolution inverse du $\mathrm{pH}$ corrobore ces résultats. L'augmentation significative de la proportion molaire de l'acide butyrique s'est faite aux dépens des acides propionique et valérique dans le cas du régime " amidon "; la concentration en acide acétique n'a pas été modifiée. L'évolution de la composition molaire des AGV est plus difficile à caractériser avec le régime " cellulose " : à une augmentation du pourcentage molaire des acides acétique et butyrique, correspond une diminution de la proportion des acides propionique et valérique. La concentration en glucides alcoolo-solubles du jus de rumen n'a jamais été influencée par la présence de $E$, tandis que les concentrations en acide 
TABLEAU 4

Evolution des différents produits terminaux de la digestion dans le rumen d'animaux recevant les régimes "cellulose " et " amidon " en fonction de la nature de la faune du rumen ( $n=24$ pour moyennes des prélèvements $\mathrm{T} 1 / 2, \mathrm{~T} 1, \mathrm{~T} 11 / 2, \mathrm{~T} 2, \mathrm{~T} 3, \mathrm{~T} 5$ ) ( $n=8$ pour moyennes des prélèvements $\mathrm{T} 11 / 2$ et $\mathrm{T} 3$ )

\begin{tabular}{|c|c|c|c|c|c|c|c|}
\hline Mesure & Régime & $(-C)$ & $(P)$ & (E) & $(P+E)$ & $(+C)$ & $\begin{array}{l}\text { erreur } \\
\text { résiduelle }\end{array}$ \\
\hline $\mathrm{pH}$ & $\begin{array}{l}\text { "cellulose " } \\
\text { " amidon " }\end{array}$ & $\begin{array}{l}6,81^{\mathrm{a}} \\
5,90^{\mathrm{a}}\end{array}$ & $\begin{array}{l}6,63^{b} \\
5,81^{a}\end{array}$ & $\begin{array}{l}6,44^{c} \\
6,11^{b}\end{array}$ & $\begin{array}{l}6,43^{\mathrm{c}} \\
5,92^{\mathrm{a}}\end{array}$ & $\begin{array}{l}6,61^{\mathrm{b}} \\
6,14^{\mathrm{b}}\end{array}$ & $\begin{array}{l}0,10 \\
0,22\end{array}$ \\
\hline $\begin{array}{c}\text { Somme des AGV } \\
(\mathrm{mM} / \mathrm{I})\end{array}$ & $\begin{array}{l}\text { " cellulose" } \\
\text { "amidon " }\end{array}$ & $\begin{array}{r}78,01^{\mathrm{a}} \\
103,03^{\mathrm{a}}\end{array}$ & $\begin{array}{r}94,9^{b} \\
117,51^{b}\end{array}$ & $\begin{array}{l}86,54^{c} \\
88,12^{c}\end{array}$ & $\begin{array}{r}86,25^{c} \\
116,73^{b}\end{array}$ & $\begin{array}{r}90,01^{\mathrm{c}} \\
115,60^{\mathrm{b}}\end{array}$ & $\begin{array}{r}6,88 \\
13,38\end{array}$ \\
\hline$C_{2}$ (p. 100) & $\begin{array}{l}\text { "cellulose " } \\
\text { "amidon " }\end{array}$ & $\begin{array}{l}72,61^{\mathrm{a}} \\
58,82^{\mathrm{a}}\end{array}$ & $\begin{array}{l}69,91^{b} \\
56,32^{b}\end{array}$ & $\begin{array}{l}73,22^{\mathrm{a}} \\
61,43^{\mathrm{c}}\end{array}$ & $\begin{array}{l}71,91^{\mathrm{a}} \\
58,91^{\mathrm{a}}\end{array}$ & $\begin{array}{l}71,60^{\mathrm{a}} \\
60,61^{\mathrm{c}}\end{array}$ & $\begin{array}{l}2,26 \\
2,00\end{array}$ \\
\hline$C_{3}(p .100)$ & $\begin{array}{l}\text { " cellulose " } \\
\text { " amidon " }\end{array}$ & $\begin{array}{l}18,63^{\mathrm{a}} \\
35,17^{\mathrm{a}}\end{array}$ & $\begin{array}{l}21,31^{\mathrm{b}} \\
31,16^{\mathrm{b}}\end{array}$ & $\begin{array}{l}18,34^{\mathrm{a}} \\
25,05^{\mathrm{c}}\end{array}$ & $\begin{array}{l}18,91^{\mathrm{a}} \\
29,94^{\mathrm{b}}\end{array}$ & $\begin{array}{l}17,25^{\mathrm{a}} \\
30,14^{\mathrm{b}}\end{array}$ & $\begin{array}{l}1,40 \\
3,22\end{array}$ \\
\hline $\mathrm{C}_{4}(\mathrm{p} .100)$ & $\begin{array}{l}\text { " cellulose " } \\
\text { " amidon " }\end{array}$ & $\begin{array}{l}4,61^{\mathrm{a}} \\
4,20^{\mathrm{a}}\end{array}$ & $\begin{array}{r}7,93^{\mathrm{b}} \\
11,34^{\mathrm{b}}\end{array}$ & $\begin{array}{r}6,51^{\mathrm{c}} \\
12,85^{\mathrm{b}}\end{array}$ & $\begin{array}{l}5,62^{\mathrm{d}} \\
9,64^{\mathrm{c}}\end{array}$ & $\begin{array}{l}6,83^{\mathrm{c}} \\
8,43^{\mathrm{c}}\end{array}$ & $\begin{array}{l}1,06 \\
2,46\end{array}$ \\
\hline$C_{5}$ (p. 100) & $\begin{array}{l}\text { "cellulose " } \\
\text { "amidon" }\end{array}$ & $\begin{array}{l}4,51^{\mathrm{a}} \\
1,80^{\mathrm{a}}\end{array}$ & $\begin{array}{l}1,62^{\mathrm{b}} \\
1,32^{\mathrm{a}}\end{array}$ & $\begin{array}{l}2,13^{b} \\
0,64^{b}\end{array}$ & $\begin{array}{l}3,04^{\mathrm{a}} \\
1,65^{\mathrm{a}}\end{array}$ & $\begin{array}{l}4,45^{\mathrm{a}} \\
0,76^{\mathrm{b}}\end{array}$ & $\begin{array}{l}1,26 \\
0,78\end{array}$ \\
\hline $\begin{array}{c}\text { Glucides alcoolo- } \\
\text { solubles } \\
(\mathrm{mg} / 100 \mathrm{ml})\end{array}$ & $\begin{array}{l}\text { " cellulose " } \\
\text { " amidon " }\end{array}$ & $\begin{array}{r}5,33^{\mathrm{a}} \\
24,14^{\mathrm{a}}\end{array}$ & $\begin{array}{r}3,02^{\mathrm{a}} \\
33,16^{\mathrm{a}}\end{array}$ & $\begin{array}{r}2,06^{\mathrm{a}} \\
26,27^{\mathrm{a}}\end{array}$ & $\begin{array}{r}2,05^{\mathrm{a}} \\
36,34^{\mathrm{a}}\end{array}$ & $\begin{array}{r}4,16^{a} \\
28,41^{a}\end{array}$ & $\begin{array}{l}1,20 \\
8,80\end{array}$ \\
\hline $\begin{array}{l}\text { Acide lactique } \\
(\mathrm{mg} / 1)\end{array}$ & $\begin{array}{l}\text { "cellulose " } \\
\text { " amidon" }\end{array}$ & $\begin{array}{r}4,31^{a} \\
336,61^{a} \\
\end{array}$ & $\begin{array}{r}4,27^{\mathrm{a}} \\
595,73^{\mathrm{b}}\end{array}$ & $\begin{array}{r}3,65^{a} \\
1806,81^{c} \\
\end{array}$ & $\begin{array}{r}4,35^{a} \\
322,29^{a}\end{array}$ & $\begin{array}{c}7,24^{\mathrm{b}} \\
1285,34^{\mathrm{abc}}\end{array}$ & $\begin{array}{r}1,40 \\
308,60\end{array}$ \\
\hline$\underset{(\mathrm{mg} / \mathrm{l})}{\mathrm{N}-\left(\mathrm{NH}_{3}\right)}$ & $\begin{array}{l}\text { " cellulose " } \\
\text { " amidon " }\end{array}$ & $\begin{array}{l}137,29^{\mathrm{a}} \\
163,61^{\mathrm{a}}\end{array}$ & $\begin{array}{l}122,31^{\mathrm{a}} \\
149,29^{\mathrm{a}}\end{array}$ & $\begin{array}{l}126,30^{\mathrm{a}} \\
248,47^{\mathrm{b}}\end{array}$ & $\begin{array}{l}169,24^{\mathrm{a}} \\
225,55^{\mathrm{b}}\end{array}$ & $\begin{array}{c}178,32^{\mathrm{b}} \\
242,24^{\mathrm{b}}\end{array}$ & $\begin{array}{l}25,60 \\
54,80\end{array}$ \\
\hline
\end{tabular}

(Les valeurs affectées de lettres différentes sont significativement différentes au seuil $P<0,05$ ).

lactique et en ammoniaque ont été fortement augmentées avec le régime " amidon ». Enfin, l'activité cellulolytique des bactéries a été accrue avec le régime " cellulose ", alors qu'elle a diminué avec le régime " amidon ".

L'inoculation simultanée de $P$ et de $E$ dans un rumen défauné a entraîné une augmentation significative de la concentration moyenne des AGV dans le rumen d'environ 10 p. 100 . Avec le régime " cellulose ", une faible augmentation de la proportion molaire en acide butyrique a été observée. Les variations de la proportion molaire des autres AGV ont été faibles et généralement non significatives. Avec le régime " amidon ", l'augmentation du pourcentage d'acide butyrique a été plus importante ; elle a été compensée par une évolution inverse de l'acide propionique. Les concentrations du jus de rumen en glucides alcoolo-solubles et en acide lactique n'ont pas été influencées par la présence de $P+E$. Par contre, la concentration en azote ammoniacal a été significativement accrue de 23 p. 100 et de 38 p. 100 respectivement avec les régimes " cellulose " et " amidon ».

La présence d'une faune conventionnelle n'a pas modifié la concentration 
totale en $\mathrm{AGV}$ par rapport à celle mesurée chez les moutons $P+E$; elle a, par contre, entraîné une élévation significative de la valeur du $\mathrm{pH}$. Chez l'ensemble de ces animaux, nous avons constaté une nette augmentation de la proportion d'acide butyrique dans le mélange des $A G V$ avec les deux régimes étudiés. Les pourcentages molaires des acides acétique et propionique ont peu évolué ; seule la diminution de la proportion d'acide propionique et la légère augmentation de l'acide acétique observées avec le régime "amidon ", ont été significatives.

D'une façon générale, la concentration en ammoniaque a été plus élevée avec les animaux à faune totale qu'avec les autres types de ciliés inoculés. II faut remarquer que cette concentration évolue dans le même sens que l'effectif des ciliés dans le rumen, ce qui tend à montrer qu'il existe une relation entre ces deux paramètres.

Seuls les animaux conventionnels $(+C)$ ont eu une concentration en acide lactique dans le jus de rumen significativement plus élevée par rapport à l'ensemble des autres lots d'animaux étudiés. La concentration en glucides alcoolosolubles du jus de rumen n'a, par contre, pas été modifiée par l'inoculation d'une faune conventionnelle, quelle que soit la nature du régime.

Enfin, l'implantation de protozoaires ciliés dans le rumen n'a eu aucune influence sur le volume du liquide du rumen dont la valeur moyenne a été respectivement de $0,280 \pm 0,002$ et $0,310 \pm 0,08$ litres par $\mathrm{kg} \mathrm{P}^{0,75}$ avec les régimes " cellulose " et " amidon ". Les modifications observées, aussi bien dans la population des ciliés qu'au niveau de la concentration des produits terminaux de la digestion, ne peuvent donc s'expliquer que par des variations de synthèse ou de production pour un régime donné.

\section{Paramètres biochimiques sanguins (tabl. 5).}

L'inoculation de ciliés dans des rumens défaunés a significativement modifié la glycémie des seuls animaux ayant reçu le régime " amidon "; l'augmentation constatée après l'inoculation des ciliés n'a pas été différente entre lots d'animaux inoculés. La nature du régime et de l'inoculum n'a eu aucun effet significatif sur la valeur de I'hématocrite.

TABLEAU 5

Evolution de la glycémie et de l'hématocrite avec la nature de la faune du rumen $(n=4)$ (prélèvements effectués à T1 h)

\begin{tabular}{|c|c|c|c|c|c|c|c|}
\hline Mesures & Régime & $(-C)$ & $(P)$ & (E) & $(P+E)$ & $(+C)$ & $\begin{array}{l}\text { erreur } \\
\text { résiduelle }\end{array}$ \\
\hline $\begin{array}{c}\text { Glycémie } \\
(\mathrm{mg} / 100 \mathrm{ml})\end{array}$ & $\begin{array}{l}\text { "cellulose " } \\
\text { "amidon " }\end{array}$ & $\begin{array}{l}58,2^{a} \\
64,4^{a}\end{array}$ & $\begin{array}{l}60,8^{a} \\
70,3^{b}\end{array}$ & $\begin{array}{l}62,1^{\mathrm{a}} \\
72,1^{\mathrm{b}}\end{array}$ & $\begin{array}{l}58,6^{\mathrm{a}} \\
70,8^{\mathrm{b}}\end{array}$ & $\begin{array}{l}53,9^{\mathrm{a}} \\
70,7^{\mathrm{b}}\end{array}$ & $\begin{array}{l}4,6 \\
3,2\end{array}$ \\
\hline $\begin{array}{l}\text { Hématocrites } \\
\text { (p. 100) }\end{array}$ & $\begin{array}{l}\text { " cellulose " } \\
\text { " amidon " }\end{array}$ & $\begin{array}{l}33,7^{\mathrm{a}} \\
31,7^{\mathrm{a}}\end{array}$ & $\begin{array}{l}36,6^{a} \\
35,7^{a}\end{array}$ & $\begin{array}{l}35,0^{\mathrm{a}} \\
33,7^{\mathrm{a}}\end{array}$ & $\begin{array}{l}36,1^{a} \\
35,7^{a}\end{array}$ & $\begin{array}{l}32,2^{\mathrm{a}} \\
35,6^{\mathrm{a}}\end{array}$ & $\begin{array}{l}2,9 \\
2,7\end{array}$ \\
\hline
\end{tabular}

(Les valeurs affectées de lettres différentes sont significativement différentes au seuil $P<0,05$ ) 


\section{Discussion}

L'importance du développement des différents ciliés dans un rumen monoinoculé, exprimée par leur concentration et surtout par leur biomasse, traduit leur aptitude à utiliser in vivo les différentes sources d'énergie mises à leur disposition. Nos résultats montrent qu'Entodinium se développe beaucoup mieux en présence d'amidon qu'en présence de cellulose. En revanche, Polyplastron est capable d'utiliser de façon comparable les deux sources de glucides. La présence simultanée des deux ciliés dans le rumen améliore essentiellement la biomasse de Polyplastron trandis qu'elle provoque une baisse de la biomasse d'Entodinium particulièrement importante avec le régime " amidon ". Ce résultat peut s'expliquer à la fois par la prédation de Polyp/astron sur Entodinium (Eadie, 1962, 1967) et par une compétition nutritionnelle entre les deux genres (Grolière_et al., 1980 ; Senaud et al., 1980). Chez les animaux conventionnels, la biomasse de Polyplastron n'est pas modifiée par rapport à celle observée chez les animaux $P+E$, alors que celle d'Entodinium a fortement augmenté. La prédation de Polyplastron sur Entodinium serait dans ce cas moins sévère puisque le prédateur peut disposer d'autres proies (/sotricha et Dasytricha).

La biomasse des ciliés chez les animaux conventionnels est beaucoup plus importante en présence d'amidon dont la vitesse d'hydrolyse est rapide, qu'avec la cellulose dont la dégradation dans le rumen est lente. Quelle que soit la nature du régime, c'est toujours le genre Entodinium qui domine dans la biomasse totale des ciliés. La part qu'il représente est d'autant plus importante, tandis que celle de Polyplastron est d'autant plus faible, que le nombre de genres présents dans le rumen est élevé. L'utilisation de l'amidon par /sotricha lui permet d'atteindre un effectif important ( $>5 \times 10^{3}$ par $\mathrm{ml}$ ) avec ce régime. Par contre la biomasse de Dasytricha reste faible, ce qui confirme sa mauvaise aptitude à utiliser l'amidon. Enfin, le développement des ciliés holotriches avec le régime "cellulose " est dû vraisemblablement à la présence de glucides solubles dans les graminées et plus particulièrement de fructosanes qu'ils peuvent fermenter (Howard, 1959 a, b).

Rôle des protozoaires ciliés dans la digestion des glucides pariétaux.

Si l'on admet que la lignine est pratiquement indigestible (Journet et Jarrige, 1962), les variations de la digestibilité apparente de la lignocellulose (ADF) sont une bonne estimation de celles de la digestibilité apparente de la cellulose. D'une manière générale, la présence de ciliés dans le rumen a augmenté la digestibilité apparente de la lignocellulose, et donc, de la cellulose. L'importance de cette augmentation a varié selon la nature du régime étudié et le genre de cilié inoculé. Ainsi lorsque les animaux ont reçu un régime à teneur élevée en hémicelluloses et en cellulose (environ 35 p. 100 de la matière organique), l'action positive de Polyplastron sur la digestibilité de la cellulose a été particulièrement nette, alors que dans le même temps l'activité cellulolytique des bactéries du rumen n'était pas significativement modifiée par rapport à celle mesurée chez les animaux sans ciliés (tabl. 6). Dans le cas du régime " amidon ", nous avons même observé une diminution de l'activité cellulolytique des bactéries chez les animaux hébergeant Polyplastron, tandis que la digestibilité de la cellulose augmentait. Polyplastron a donc eu un effet direct sur la digestion de la cellulose. Des études déjà anciennes ont 
TABLEAU 6

Signification des effets " protozoaires " et "régimes", ainsi que leurs interactions, sur les principaux paramètres digestifs par analyse factorielle à 3 niveaux $(2 \times 2 \times 2)$

\begin{tabular}{|c|c|c|c|c|c|c|c|}
\hline \multirow[b]{3}{*}{ Paramètre } & \multicolumn{7}{|c|}{ Signification des effets } \\
\hline & \multicolumn{4}{|c|}{ effets simples } & \multicolumn{3}{|c|}{ interactions } \\
\hline & $\begin{array}{c}\text { "Polyplas- } \\
\text { tron " }\end{array}$ & $\begin{array}{l}\text { "Ento- } \\
\text { dinium } "\end{array}$ & régime & répétitions & $\begin{array}{c}\text { "Polyplas- } \\
\text { tron " et } \\
\text { "Entodinium" }\end{array}$ & $\begin{array}{l}\text { "Polyplas- } \\
\text { tron » et } \\
\text { régime }\end{array}$ & $\begin{array}{l}\text { "Ento- } \\
\text { dinium " } \\
\text { et régime }\end{array}$ \\
\hline & $P<$ & $\mathrm{P}<$ & $\mathbf{P}<$ & $P<$ & $P<$ & $P<$ & $P<$ \\
\hline CUD MO & 0,01 & 0,05 & 0,01 & N.S. & N.S. & N.S. & N.S. \\
\hline CUD ADF & 0,01 & 0,05 & 0,01 & N.S. & N.S. & N.S. & N.S.* \\
\hline \multicolumn{8}{|l|}{$\begin{array}{l}\text { Activité cellulolytique } \\
\text { des bactéries du }\end{array}$} \\
\hline & 0,05 & 0,01 & 0,01 & N.S. & N.S. & 0,01 & 0,01 \\
\hline $\mathrm{pH}$ jus de rumen .... & 0,05 & 0,05 & 0,01 & N.S. & N.S. & N.S. & 0,01 \\
\hline Concentration totale & 0,01 & 0,05 & 0,01 & N.S. & N.S. & 0,05 & N.S. \\
\hline$c_{2}$ (p. 100 molaire) & 0,05 & 0,05 & 0,01 & N.S. & N.S. & N.S. & N.S. \\
\hline $\mathrm{C}_{3}$ (p. 100 molaire) & 0,05 & 0,05 & 0,01 & N.S. & N.S. & N.S. & 0,01 \\
\hline $\mathrm{C}_{4}$ (p. 100 molaire) & 0,05 & 0,05 & 0,01 & N.S. & 0,01 & N.S. & 0,05 \\
\hline $\mathrm{C}_{5}^{4}$ (p. 100 molaire) & 0,05 & 0,01 & 0,05 & N.S. & 0,01 & 0,05 & 0,05 \\
\hline \multicolumn{8}{|l|}{$\begin{array}{l}\text { Glucides alcoolo-solu- } \\
\text { bles dans ius de }\end{array}$} \\
\hline $\begin{array}{l}\text { bles dans jus de } \\
\text { rumen } \ldots \ldots \ldots \ldots\end{array}$ & N.S. & N.S. & 0,01 & N.S. & N.S. & N.S. & N.S. \\
\hline \multicolumn{8}{|c|}{ Acide lactique dans } \\
\hline jus de rumen ..... & 0,05 & 0,05 & 0,01 & N.S. & 0,05 & 0,05 & 0,05 \\
\hline $\mathrm{N}-\mathrm{NH}_{3}$ jus de rumen & N.S. & 0,01 & 0,01 & N.S. & N.S. & N.S. & 0,05 \\
\hline Glycémie ......... & 0,05 & 0,01 & 0,01 & N.S. & N.S. & N.S. & 0,01 \\
\hline Hématocrites. & N.S. & N.S. & N.S. & N.S. & N.S. & N.S. & N.S. \\
\hline
\end{tabular}

montré que ce cilié est capable d'ingérer des fibres cellulosiques (Hungate, 1943 ; Sugden, 1953 ; Hungate, 1966). En outre, Abou Akkada, Eadie et Howard (1963) ont mis en évidence, dans les broyats de Polyplastron isolés d'un rumen contenant d'autres ciliés, l'existence d'une cellulase capable d'hydrolyser de la cellulose native. Grâce à l'utilisation d'animaux mono-contaminés avec l'espèce P. multivesiculatum nous démontrons, in vivo, et pour la première fois à notre connaissance, l'intervention vraisemblable de ce cilié dans la digestion des parois végétales.

Le rôle d'Entodinium $s p$. dans la digestion de la cellulose n'a jamais été clairement établi. La majorité des études réalisées in vitro (Abou Akkada, Hobson et Howard, 1959 ; Abou Akkada et Howard, 1960) ont montré qu'Entodinium sp. ne possède pas de cellulase. Seule Bonhomme-Florentin (1975) a mis en évidence l'existence d'une polyglucosidase de type $C x$ qui dégrade partiellement les celluloses substituées telles que la carboxyméthylcellulose ; par contre aucune activité cellulolytique de type $C_{1}$ n'a pu être observée. Nos résultats montrent qu'avec le régime " cellulose " l'amélioration de la digestibilité de la cellulose, après l'inoculation d'Entodinium sp., n'est pas significative, bien que l'activité cellulolytique des bactéries ait été accrue. Après le régime " amidon ", pour lequel les quantités 
de cellulose et d'hémicelluloses ingérées ont été faibles $\left(12 \mathrm{~g} / \mathrm{kg} \mathrm{P}^{0,75}\right)$, l'action d'Entodinium sur la digestibilité de la lignocellulose a été significativement positive et égale à celle de Polyplastron. Les deux genres de ciliés, qui ont également diminué l'activité cellulolytique des bactéries, se comportent donc de façon identique à l'égard de la cellulose présente dans le régime " amidon ". Ceci semble indiquer que la capacité d'Entodinium à digérer la cellulose est limitée. Cette digestion sera relativement importante dans le cas des régimes à faible teneur en cellulose digestible (régime " amidon »); Entodinium aura par contre un effet limité sur la digestibilité de la cellulose avec les régimes à base de fourrages grossiers. L'analyse factorielle des paramètres caractérisant le pouvoir cellulolytique comparée des ciliés confirme cette différence entre $P$ et $E$ (tabl. 6). Les effets positifs de Polyplastron et d'Entodinium sur la digestibilité de la cellulose ne sont pas additifs chez les animaux $P+E$ et $(+C)$ qui reçoivent le régime " amidon " (tabl. 3). Ce résultat s'explique par une diminution sensible de l'activité cellulolytique des bactéries chez ces deux derniers lots d'animaux. Avec le régime " cellulose ", l'addition d'Entodinium à Polyp/astron ne modifie ni la digestibilité de la cellulose, ni l'activité cellulolytique des bactéries, ce qui est confirmé par l'analyse factorielle des interactions $P$ et $E$ (tabl. 6).

D'une manière générale, l'activité cellulolytique des bactéries du rumen a été accrue par la présence de ciliés lorsque les animaux ont reçu le régime " cellulose »; par contre, elle a diminué avec le régime " amidon ». Ces résultats contradictoires peuvent s'expliquer dans le cas du régime "cellulose " par une activation du métabolisme des bactéries cellulolytiques qui composent la majorité de la population microbienne. Ce résultat confirme ceux de Abou Akkada et El Shazly, 1964 ; Borhami et al., 1967 ; l'activation serait due à la prédation des bactéries par les ciliés comme l'ont indiqué Kurihara et al. (1968). Dans le cas du régime " amidon ", les conditions physico-chimiques du milieu $(\mathrm{pH}$, substrat énergétique...) ne sont pas favorables au développement des bactéries cellulolytiques. La diminution de leur effectif en présence de prédateurs que sont les ciliés ne peut donc pas être compensée par une accélération de la division cellulaire comme c'est vraisemblablement le cas avec le régime « cellulose ». Les intéractions " hôte-bactériesprotozoaires " sont très étroites et la modification d'un seul de ces paramètres entraîne probablement des variations importantes sur l'ensemble de l'écosystème que constitue le rumen.

\section{Róle des protozoaires ciliés dans la digestion de l'amidon.}

De nombreux auteurs (Nakamura et Kanegasaki, 1969 ; Bonhomme et Durand, 1974 ; Jouany et al., 1977 ; Grolière et al., 1980 ; Senaud et al., 1980) ont montré qu'Entodinium utilise l'amidon. L'importance de la biomasse d'Entodinium observé avec le régime " amidon " confirme ce résultat.

Les rares travaux effectués sur Polyplastron ont permis de montrer qu'il pouvait également digérer l'amidon (Abou Akkada, 1965). Selon Abou Akkada, Eadie et Howard (1963), Polyplastron possède une amylase capable de dégrader l'amidon natif. En outre, sa taille lui permet d'ingérer de grandes quantités de grains d'amidon qui seront ensuite digérées dans l'endoplasme (Hungate, 1966). Toutefois, la digestibilité apparente de l'amidon, qui a été totale quelle qu'ait été la 
nature de la faune du rumen ne nous permet pas de próciser le rôle respectif de Polyplastron ou d'Entodinium. L'utilisation d'un amidon plus difficilement dégradable (mais par exemple) et distribué en quantités plus importantes, aurait peutêtre permis de préciser l'action des différents ciliés étudiés sur sa digestion. /sotricha peut ingérer, puis digérer les grains d'amidon présents dans le rumen (Heald et Oxford, 1953 ; Howard, 1959 a). Dasytricha comme /sotricha possède une alpha-amylase (Mould et Thomas, 1958), mais il ne peut pas ingérer les grains d'amidon à cause de sa petite taille (Hungate, 1966) ; il agit essentiellement sur la fermentation du maltose produit à partir de l'amidon (Mould et Thomas, 1958).

Produits terminaux de la digestion dans le rumen.

La présence de ciliés dans le rumen a, dans la majorité des cas, provoqué une augmentation de la concentration des AGV dans le jus de rumen, laquelle a varié comme la digestibilité de la ration. Ce résultat traduit, d'une part l'existence d'une fermentation propre des ciliés qui s'ajoute à celles des bactéries et, d'autre part une activation du métabolisme des bactéries chez les animaux faunés (Kurihara et al., 1968).

Seuls les animaux mono-inoculés avec "Entodinium " et recevant le régime " amidon " ont eu une évolution inverse. La diminution de la concentration des AGV peut s'expliquer à la fois par l'ingestion rapide des grains d'amidon par la majorité des ciliés appartenant au genre "Entodinium », à l'exception des espèces de petite taille (Coleman, 1969 a), et par la diminution du nombre de bactéries observé chez les animaux faunés (Eadie et Hobson, 1962 ; Gutierrez et Hungate, 1957 ; Gutierrez, 1958). Une partie de l'amidon ingéré est utilisée pour constituer des réserves qui seront ensuite fermentées in situ ou digérées dans le duodénum avec les ciliés qui quittent le rumen. L'augmentation significative de la glycémie chez les animaux faunés peut expliquer ce dernier phénomène puisque la néoglucogénèse n'est certainement pas accrue en présence de ciliés, la production d'acide propionique ayant diminué. En outre, Abou Akkada et Howard (1960) ont montré que les processus fermentaires dans Entodinium sp. sont lents car l'absorption des enzymes sur le substrat à l'intérieur du cilié est faible. Cela conduit à une production d'AGV plus régulière dans le temps chez les animaux faunés avec le genre Entodinium. Les ciliés peuvent donc jouer un rôle de régulateur dans le rumen, d'une part en réduisant l'intensité des fermentations dans le cas de régimes riches en amidon et, d'autre part en étalant la digestion au cours de la journée (fig. 2). Ce résultat, bien qu'obtenu sur un nombre limité d'animaux, coïn-
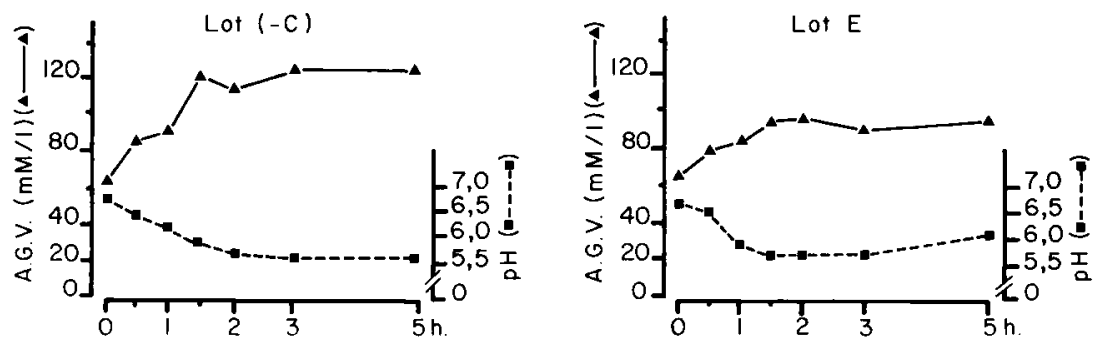

FIG. 2. - Valeur du $p H$ et concentration en acides gras volatils totaux du jus de rumen (régime " amidon $»)$. 
cide avec plusieurs observations déjà faites dans notre laboratoire (Collombier, 1981) ou à l'étranger (Whitelaw et al., 1970).

La modification de la composition du mélange des AGV induite par l'inoculation de ciliés dans le rumen est comparable à celle décrite par la plupart des auteurs en ce qui concerne le butyrate (Christiansen, Kawashima et Burroughs, 1965 ; Luther, Trenkle et Burroughs, 1966 ; Youssef et Allen, 1968 ; Eadie et Mann, 1970 ; Males et Purser, 1970 ; Eadie et Gill, 1971). Les variations des proportions d'acétate et de propionate sont plus difficiles à caractériser et à comparer aux données de la biblịographie qui sont souvent contradictoires. L'analyse factorielle de ces paramètres a toutefois permis de mettre en évidence un effet spécifique à chaque genre de cilié étudié (tabl. 6). Nous constatons que les effets évoluent en fonction de la nature de la faune et du type de régime étudiés. C'est pourquoi, la composition qualitative et quantitative de la faune du rumen doit être précisée au même titre que la ration alimentaire si l'on veut expliquer les différences observées au niveau des produits terminaux de la digestion dans le rumen. En outre, les interrelations protozoaires-bactéries introduisent également un facteur de variation supplémentaire, qui reste à ce jour peu connu, mais qui est probablement déterminant dans la formation des différents AGV. Enfin, l'augmentation de la concentration en ammoniaque observée chez les animaux inoculés, qui correspond également aux données de la bibliographie (Abou Akkada et El Shazly, 1964 ; Christiansen, Kawashima et Burroughs, 1965 ; Klopfenstein, Purser et Tyznik, 1966 ; Borhami et al., 1967 ; Kurihara et al., 1968 ; Males et Purser, 1970 ; Eadie et Gill, 1971 ; Itabashi et Kandatsu, 1975) s'explique à la fois par une dégradation des protéines alimentaires (Warner, 1955 ; Williams et al., 1961) et bactériennes (Gutierrez et Hungate, 1957 ; Gutierrez, 1958 ; Coleman, 1975) ingérées par les ciliés.

En conlusion, la présence de ciliés dans le rumen peut donc être considérée comme un facteur positif dans la digestion des glucides pariétaux, et plus particulièrement de la cellulose. Ils peuvent également avoir un effet tampon sur les fermentations de l'amidon en évitant une production trop importante d'acides gras volatils après le repas et en l'étalant au cours de la journée. Cependant, leur action sur le métabolisme de l'animal, et sur l'utilisation de l'azote en particulier, est aujourd'hui controversée (cf. revue de Coleman, 1979).

Reçu en juin 1981.

Accepté en mars 1982.

\section{Références}

ABOU AKKADA A. R., 1965. The metabolism of ciliate protozoa in relation to rumen function, 335-345. In DOUGHERTY R. W. Physiology of digestion in the ruminant. Butterworths, London.

ABOU AKKADA A. R., EADIE J. M., HOWARD B. H., 1963. The biochemistry of rumen protozoa : 7 - The carbohydrases of Polyplastron multivesiculatum. Biochem. J., 89, 268-272. 
ABOU AKKADA A. R., EL SHAZLY K., 1964. Effect of absence of ciliate protozoa from the rumen on microbial activity and growth of lambs. Appl. Microbiol., 12, 384-390.

ABOU AKKADA A. R., HOBSON P. N., HOWARD B. H., 1959. Carbohydrate fermentation by rumen protozoa of genus Entodinium. Biochem. J., 73, 44P-45P.

ABOU AKKADA A. R., HOWARD B. H., 1960. The biochemistry of rumen protozoa : 3 - The carbohydrate metabolism of Entodinium. Biochem. J., 76, 445-451.

BARKER S. B., SUMMERSON W. M., 1941. The colorimetric determination of lactic acid in biological material. J. biol. Chem., 138, 535-554.

BESLE J. M., 1974. Séparation des oses, des di et triholosides par chromatographie d'échange d'ions. Ann. Biol. anim. Bioch. Biophys., 14, 545-573.

BONHOMME A., DURAND M., 1974. Variations qualitatives et quantitatives de la faune du rumen du mouton en fonction de la nature du régime. Ann. Biol. anim. Bioch. Biophys., 14, 679 687.

BONHOMME-FLORENTIN A., 1975. Activité cellulolytique des ciliés Entodiniomorphes J. Protozool., 22, 447-451.

BORHAMI B. E. A., EL SHAZLY K., ABOU AKKADA A. R., AHMED I. A., 1967. Effect of early establishment of ciliate protozoa in the rumen on microbial activity and growth of early weaned buffalo calves. J. Dairy Sci., 50, 1654-1660.

CHARPENTIER J., 1966. Pigmentation musculaire du veau de boucherie : I - Facteurs de variations. Ann. Zootech., 15, 181-196.

CHRISTIANSEN W. C., KAWASHIMA R., BURROUGHS W., 1965. Influence of protozoa upon rumen acid production and liveweight gains in lambs. J. anim. Sci., 24, 730-734.

CLARKE R. T. J., 1963. The cultivation of some rumen Oligotrich protozoa. J. gen. Microbiol., 33, 401-408. .

COLEMAN G. S., 1960. The cultivation of sheep rumen Oligotrich protozoa in vitro. J. gen. Microbiol., 22, 555-563.

COLEMAN G. S., 1969 a. The metabolism of starch, maltose, glucose and some other sugars by the rumen ciliate Entodinium caudatum. J. gen. Microbiol., 57, 303-332.

COLEMAN G. S., 1969 b. The cultivation of the rumen ciliate Entodinium simplex. J. gen. Microbiol., 57, 81-90.

COLEMAN G. S., 1970. Studies of the rumen ciliate Entodinium caudatum. Agric. Res. Counc., Inst. anim. Physiol., 101-102.

COLEMAN G. S., 1975. The interrelationship between rumen ciliate protozoa and bacteria, 149-164. In McDONALD I.W., WARNER A. C. I. Digestion and metabolism in the ruminant. Univ. New-England Pub. Unit.

COLEMAN G. S., 1979. The role of rumen protozoa in the metabolism of ruminants given tropical feeds. Trop. anim. Prod., 4, 199-213.

COLEMAN G. S., DAVIES J. I., CASH M. A., 1972. The cultivation of the rumen ciliates Epidinium ecaudatum caudatum and Polyplastron multivesiculatum in vitro. J. gen. Microbiol., 73. 509521.

COLLOMBIER J., 1981. Contribution à l'étude du rôle des protozoaires ciliés du rumen dans l'apport $d^{\prime}$ azote microbien entrant dans le duodenum du ruminant. Th. Doct.-Ing. $n^{\circ} 105$, Série D.I., Univ. Clermont II, 85 pp.

DEMARQUiLLY C., CHENO OT M., 1969. Etude de la digestion des fourrages dans le rumen par la méthode des sachets de nylon. Liaisons avec la valeur alimentaire. Ann. Zootech., 18, 419 436.

EADIE J. M., 1962. Inter-relationships between certain rumen ciliate protozoa. J. gen. Microbiol., 29, 579-588.

EADIE J. M., 1967. Studies on the ecology of certain rumen ciliate protozoa. J. gen. Microbiol., 49, 175-194.

EADIE J. M., GILL J. C., 1971. The effect of the absence of rumen ciliate protozoa on growing lambs fed on a roughage-concentrate diet. Br. J. Nutr., 26, 155-167.

EADIE J. M., HOBSON P. N., 1962. Effect of presence or absence of ciliates on the total rumen bacterial counts in lambs. Nature, 193, 503-505.

EADIE J. M., HOWARD B. H., 1963. Rumen ciliate protozoology, 57-58. In CUTHBERTSON D. P. Progress in nutrition and allied sciences. Oliver and Boyd Pub. Co. 
EADIE J. M., MANN S. O., 1970. Development of the rumen microbial population : high starch diets and instability, 335-347. In PHILLIPSON A. T. Physiology of digestion and metabolism in the ruminant. Oriel Press, England.

GROLIĖRE C. A., SENAUD J., JOUANY J. P., GRAIN J., DE PUYTORAC P., 1980. Implantation et développement des populations de protozoaires ciliés (Polyplastron multivesiculatum, Entodinium sp., (sotricha prostomal dans le rumen de moutons recevant différents régimes alimentaires : II - Régimes à base de foin, enrichis en céréales. Protistologica, 16, 385-394.

GUTIERREZ J., 1958. Observations on bacterial feeding by the rumen ciliate Isotricha Prostoma. J. Protozool., 5, 122-126.

GUTIERREZ J., DAVIS R. E., 1962. Culture and metabolism of the rumen ciliate Epidinium ecaudatum Crawley. Appl. Microbiol., 10, 305-308.

GUTIERREZ J., HUNGATE R. E., 1957. Interrelationship between certain bacteria and the rumen ciliate Dasytricha ruminantium. Science, 126, 511.

HEALD P. J., OXFORD A. E., 1953. Fermentation of soluble sugars by anaerobic holotrich ciliate protozoa of the genera Isotricha and Dasytricha. Biochem. J., 53, 506-512.

HOWARD B. H., 1959 a. The biochemistry of rumen protozoa : 1 - Carbohydrate fermentation by Dasytricha and Isotricha. Biochem. J., 71, 671-675.

HOWARD B. H., $1959 \mathrm{~b}$. The biochemistry of rumen protozoa: 2 - Some carbohydrases in cell-free extracts of Dasytricha and Isotricha. Biochem. J., 71, 675-680.

HUNGATE R. E., 1942. Cité par HUNGATE (1966).

HUNGATE R. E., 1943. Further experiments on cellulose digestion by the protozoa in the rumen of cattle. Biol. Bull., 84, 157-163.

HUNGATE R. E., 1955. Mutualistic intestinal protozoa. Biochem. Physiol. Protoz., 2, 159-199. Acad. Press, New-York, London.

HUNGATE R. E., 1966. The rumen and its microbes. Acad. Press, New-York, San Francisco, London.

HYDEN S., 1955. A turbidimetric method for the determination of higher polyethylene glycols in biological materials. Ann. K. Lantbröghs., 22, 139-145.

HYDEN S., 1961. Determination of the amount of fluid in the reticulo-rumen of the sheep and its passage to the omasum. Kungl. Lantb. Ann., 27, 51-79.

ITABASHI H., KANDATSU M., 1975. Influence of rumen ciliate protozoa on the concentration of ammonia and volatile fatty acids in connection with the utilization of ammonia in the rumen. Jap. J. Zootech. Sci., 46, 405-416.

JARRIGE R., 1961. Analyse des constituants glucidiques des plantes fourragères. 1 - Fractionnement des constituants de la membrane par les hydrolyses acides. Ann. Biol. anim. Bioch. Biophys., 1, 163-212.

JOUANY J. P., 1978. Contribution à l'étude des protozoaires ciliés du rumen : leur dynamique, leur róle dans la digestion et leur intérêt pour le ruminant. Th. Doct. Etat, $\mathrm{n}^{\circ} \mathrm{d}^{\prime}$ ordre 256. Univ. Clermont II. 2 vol., 195 p. + 101 fig. + 60 tabl.

JOUANY J. P., SENAUD J., GRAIN J., DE PUYTORAC P., THIVEND P., 1977. Rumen ciliates of sheep given cellulose, lactose, sucrose or starch diets. Proc. Nutr. Soc., 36, 72A.

JOURNET M., JARRIGE R., 1962. Analyse des constituants glucidiques des plantes fourragères : III - Etude sur le dosage de la lignine. Ann. Biol. anim. Bioch. Biophys., 2, 223-250.

KLOPFENSTEIN T. J., PURSER D. B., TYZNIK W. J., 1966. Effects of defaunation on feed digestibility, rumen metabolism and blood metabolites. J. anim. Sci., 25, 765-773.

KURIHARA Y., EADIE J. M., HOBSON P. N., MANN S. O., 1968. Relationship between bacteria and ciliate protozoa in the sheep rumen. J. gen. Microbiol., 51, 267-288.

LUTHER R., TRENKLE A., BURROUGHS W., 1966. Influence of rumen protozoa on volatile acid production and ration digestibility in lambs. J. anim. Sci., 25, 1116-1122.

MAH R. A., 1964. Factors influencing the in vitro culture of the rumen ciliate Ophryoscolex purkynei Stein. J. Protozool., 11, 546-552.

MALES J. R., Purser D. B., 1970. Relationship between rumen ammonia levels and the microbial population and volatile fatty acid proportions in faunated and defaunated sheep. Appl. Microbiol., 19, 485-490. 
MICHEL M. M., 1971. Analyse quantitative de quelques substances azotées et glucidiques en milieu biologique. Essai de rationalisation. Th. Univ., Clermont-Ferrand, $n^{\circ} d^{\prime}$ ordre $43-$ 79 pages.

MOULD D. L., THOMAS G. J., 1958. The enzymatic degradation of starch by Holotrich. from sheep rumen. Biochem. J., 69, 327-337.

NAKAMURA K., KANEGASAKI S., 1969. Densities of ruminal protozoa of sheep established under different dietary conditions. J. Dairy Sci., 52, 250-252.

OXFORD A. E., 1955. The rumen ciliate protozoa: their chemical composition, metabolism requirements for maintenance and culture, and physiological significance for the host. Exp. Parasitol., 4, 569-605.

PRINS R. A., CLARKE R. T. J., 1979. Microbial ecology of the rumen, 179-204. In : RUCKEBUSCH Y. et THIVEND P. Digestive physiology and metabolism in ruminants. MTP Press Ltd. Pub.

SENAUD J., GROLIĖRE C. A., ZAINAB B., GRAIN J., JOUANY J. P., 1980. Implantation et développement des populations de protozoaires ciliés (Polyplastron multivesiculatum, Entodinium sp., Isotricha prostoma) dans le rumen de moutons recevant différents régimes alimentaires : I - Régime luzerne-orge (40/50). Protistologica, 16, 325-337.

SNEDECOR G. W., COCHRAN W. G., 1971. Classification à une voie, analyse de variance. In Méthodes statistiques $6^{\mathrm{e}}$ ed. Assoc. Coord. Techn. Agric. Paris, 287-333.

SUGDEN B., 1953. The cultivation and metabolism of Oligotrich protozoa from the sheep's rumen. J. gen. Microbiol., 9, 44-53.

THIVEND P., MERCIER C., GUILBOT A., 1965. Dosage de l'amidon dans les milieux complexes. Ann. Biol. anim. Bioch. Biophys., 5, 513-526.

TRINDER P., 1969. Determination of blood glucose using an oxidase-peroxidase system with a non carcinogenic chromogen. Ann. clin. Biochem., 6, 24-27.

VAN SOEST P. J., 1963. Use of detergents in analysis of fiber and lignin. J. Assoc. off. Analyt. Chem., 46, 829-835.

WARNER A. C. I., 1955. Some aspects of the nitrogen metabolism of the micro-organisms of the rumen with special references to proteolysis. Ph. D. Thes., Univ. of Aberdeen. Scotland.

WARNER A. C. I., 1962. Some factors influencing the rumen microbial population. J. gen. Microbiol., 28, 129-146.

WEATHERBURN M. W., 1967. Phenol-hypochlorite reaction for determination of ammonia. Analyt. Chem., 39, 971-974.

WHITELAW F. G., HYLDGAARD-JENSEN J., REID R. S., KAY M. G., 1970. Volatile fatty acid production in the rumen of cattle given an all-concentrate diet. Br. J. Nutr., 24, 179-195.

WILLIAMS P. P., DAVIS R. E., DOETSCH R. N., GUTIERREZ J., 1961. Physiological studies of the rumen protozoa Ophryoscolex caudatus Eberlein. J. Appl. Microbiol., 9, 405-409.

WILLIAMS P. P., DINUSSON W. E., 1972. Amino acid and fatty acid composition of bovine ruminal bacteria and protozoa. J. anim. Sci., 36, 151-155.

YOUSSEF F. G., ALLEN D. M., 1968. Role played by ciliate protozoa in rumen function. Nature, 217, 777-778. 